\title{
Investigation of Local Voltage Control Solutions for the Integration Renewable Power Sources into the Low-Voltage Networks
}

\author{
Artjoms Obushevs, Fabian Carigiet, Franz Baumgartner, Petr Korba \\ Institute of Energy Systems and Fluid Engineering \\ Zurich University of Applied Sciences \\ Winterthur, Switzerland \\ obus(cari)(bauf)(korb)@zhaw.ch
}

\begin{abstract}
This paper is devoted to the problem of voltage limits violations in low-voltage networks with high share of renewable power sources and provides a vision and comparison of different technologies based on their advantages and disadvantages and classification of technical methods for performing cost effective control in the various distribution grids categories. It was carried out based on the proposed methodology, which covers a wide range of technical solutions, to have a clear comparative analysis between different solutions. Technical and economical comparison between the results gained from the load flow calculations in Matpower and the additional functionalities provided from the OpenDSS were used to classify smart grid solutions for various low voltage distribution grids categories and to generate the ranking matrix.
\end{abstract}

Keywords-Active and reactive power control, battery energy storage system, demand side management, low-voltage distribution grid, photovoltaic, smart grids, voltage control

\section{INTRODUCTION}

The Swiss Government has targeted various changes in the policies and regulations related to the electricity production in Switzerland. Some modifications include reduction of greenhouse gas emissions, increase industrial process efficiency and decommissioning of the existing nuclear power plants by 2035. Taking into account the objectives of the Swiss energy strategy for 2050 [1], a considerable increase in the installation of Distributed Generation (DG) is forecasted. The current Renewable Energy Sources (RES) (mainly photovoltaic (PV)) volume targets of the 2050 energy strategy are not aligned with the climate targets. The goals become more ambitious, by 2035 increase from 11.4 to $26 \mathrm{TWh}$ is announced, by 2050, a new goal of $45 \mathrm{TWh}$ is to be striven for [2]. Study of SFOE confirms that the Swiss energy turnaround is feasible by increasing the number of PV installations till $82 \mathrm{TWh}[3]$.

The integration of DG has changed the assumption of having only mono-directional power flows on low voltage distribution grids (LVDG), where electricity was flowing from medium voltage (MV) grids to end-customers through the LV grid. The actual distribution grids were built in radial form defining the highest voltage node of the LV grid at the $\mathrm{MV} / \mathrm{LV}$ transformer secondary side, and the lowest voltage node at the last connection point served by the string. The impact of this policy influences the actual distribution grid, aggravating unexpected issues in defined regions with high penetration of RES. The most important implications to be considered are thermal overloading of lines, power quality issues and violations of voltage limits.

In this paper, the technical performance and economic efficiency of solutions for local voltage control (VC) in distribution grids with large fractions of RES was developed and evaluated. This was carried out based on the analysis of existing distribution grids and implementation of different solutions: classical grid reinforcement, active and reactive power control $(\mathrm{Q}(\mathrm{V}), \mathrm{PQ}(\mathrm{V}))$, line voltage regulator (LVR), onload tap changer (OLTC), battery energy storage system (BESS) and demand side management (DSM) are analysed technically using load flow simulations. After that, the economic analyses are performed resulting in a technoeconomic assessment for each grid class. Investigated grid classes are small/medium industries, near the city outskirts, urban settlements, village centres/peripheries and hamlets. The main goals described in this paper are achieved results with a proposed method for the estimation of the most costeffective solutions of VC for a specific LVDG category. The main motivation behind this work is to enable the integration of a large amount of RES without expensive grid extensions, to fulfil the given power quality standards according to VSE [4] and EN 50160 [5], and to protect the infrastructure.

Work structure is following. In the second chapter, the applied methodology of the work is described. The third chapter presents analysed VC solutions and made assumptions. Fourth chapter provide investigation of $\mathrm{VC}$ solutions using Artificial LVDG. In fifth chapter, results are summarised for various LVDG categories in ranking matrix. In the final chapter, the interpretation of the results and a discussion of the identified impacts of PV on LVDG are propounded and elucidated.

\section{Methodology}

Optimisation of low voltage systems makes it necessary to apply systems analysis and dynamic multi-step methods to observe reciprocal interconnections and behaviour of low voltage system elements over time and space. A characteristic feature of systems analysis is that for selecting an optimal solution for VC purposes, sophisticated systems must be investigated within the development process. To realize this kind of approach, modelling methods of the existing low voltage system development was used [6].

In the literature, there are many results analysing positive and negative aspects about RES impact on distribution grids with possible solutions to control voltage within the acceptable boundaries by Stetz et al. [7], IEA-PVPS [8], Hashemi et al. [9], Bayer et al. [10]. However, provided solutions with different technologies do not provide a clear comparative analysis between different solutions in middle and long-term horizon for different LVDG categories. To overcome this particular drawback, this paper provides an extended method proposed by Carigiet et al. [11] for the estimation of the most cost-effective solutions of VC for a specific LVDG category, which was elaborated for the various grid categories and a number of technical methods for performing VC. 
The simulation of LVDG is particularly challenging due to uncertain information about load patterns, non-symmetry between phases, rapid and unpredictable fluctuations of RES. In addition, the simulation of novel control mechanisms and elements, acting on RES production and other converter-based production devices requires a flexible simulation environment. To overcome these issues and observe realistic behaviour of LVDG with different solutions for VC, dynamic simulation is organized in interaction with the ZHAW developed and EPRI [12] simulation environments with a tailored capability to perform quasi-static time series simulations (QSTS). The main advantage of using QSTS simulation is its capability to properly assess and capture the time-dependent aspects of power flow, taking into account the behaviour of different solutions for VC in a yearly basis.

The method based on the deterministic concept with a dynamic low voltage planning with technical and market economic regulation principles. The mathematical model of the low voltage system and its development process configuration and network dynamic behaviours introduction provide the capability to calculate and assess system criteria for decision making. The following functional specifications of the proposed method are considered (see Figure 1).

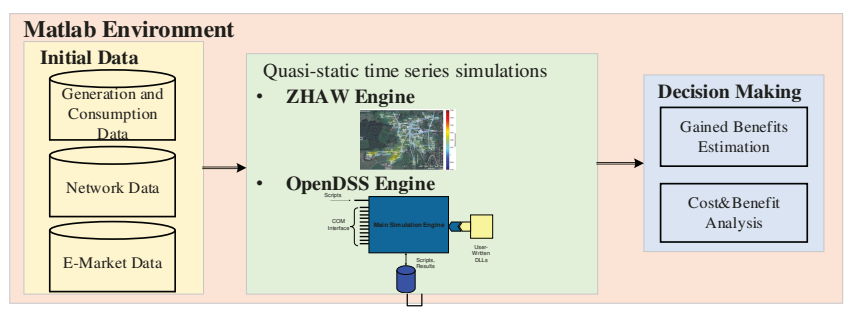

Fig. 1. Functional specification of the proposed method

First block contains the necessary input data from generators, consumers, network elements and e-market information. The Second block is concerned with obtaining the results for scenarios formed by the user, where QSTS algorithm is implemented by ZHAW using Matpower environment and OpenDSS engines. ZHAW engine is used to calculate $\mathrm{Q}(\mathrm{V}), \mathrm{PQ}(\mathrm{V}), \mathrm{P} \_\mathrm{BESS}(\mathrm{V})$ and OpenDSS for LVR, OLTC, grid reinforcements solutions. Third block is concerned as decision making, by itself is a complex procedure, and in this paper is focus on gained benefits and investment cost estimation. Discounting is done using the average cost of capital (WACC) for grid investment, which was set by UVEK [13] for the year 2019 at 3.83\%

\section{VC SOLUTIONS IN DISTRIBUTION GRIDS}

\section{A. Grid enhancement}

Investments in grid enhancement are the common way to improve the voltage regulation at the end of a string as depicted in Figure 2. The results denoted by this technical solution are easily tangible, but its investments tend to be high arousing the necessity of new solutions. The costs are assumed in range from 150 to $400 \mathrm{CHF} / \mathrm{m}$ for grid reinforcement according to different studies from [14]-[16]. Although, other type of issues like overcurrents, short circuit currents, losses on the line and stability of the system also lead to the requirement of grid reinforcement, these investments in grid reinforcement represent a major economic effort for the DSO. Nevertheless, in some cases this method provides the best economical solution. For other VC solutions implementation, additional costs are assumed in addition to capital expenditures according to [17] and is presented in Table I.

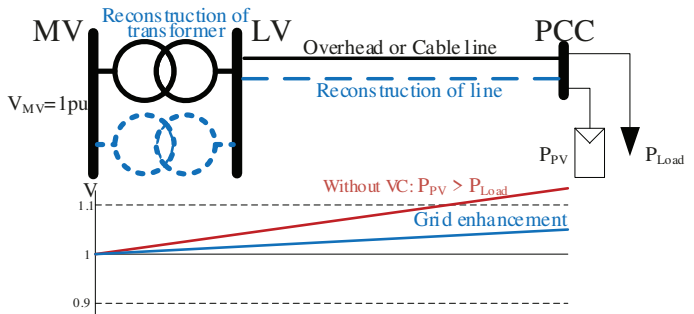

Fig. 2. Grid enhancement approach

TABLE I. ADDITIONAL COSTS FOR VC SOLUTIONS IMPLEMENTATION

\begin{tabular}{|l|c|}
\hline Various jobs for technology implementation & $15 \%$ \\
\hline Unforeseen costs & $10 \%$ \\
\hline Project Planning costs & $10 \%$ \\
\hline Construction Management / NIS Adm. Work & $8 \%$ \\
\hline
\end{tabular}

\section{B. VC with OLTC}

Tap changers are a traditional component of the actual HV/MV transformers (MV/LV case depicted in Figure 3), which enabling $\mathrm{VC}$ on the distribution grids, but at the same time, its effect involves has an impact on large areas of the distribution grid. The lack of selectivity on the VC might regulate decrease the frequency of voltage violations over a part of the grid, but, increasing them in other parts of the affected region. For the OLTC impact investigation, a voltage regulator with a standard control range of $\pm 5 \%$ or $\pm 20 \mathrm{~V}$ is used. The control range comprises 11 steps with 4-volt deadband. This corresponds to a gradation of \pm 5 steps and is implemented on the primary side of the transformer. Per stage, the secondary voltage thus changes by $\pm 1.2 \%$.

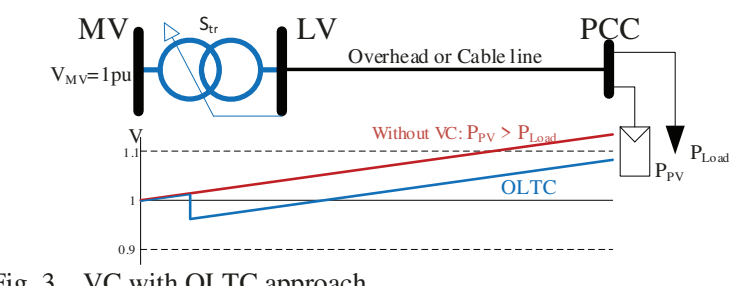

The price for an OLTC with a standard control range are assumed according to [18]:

TABLE II. CAPITAL COSTS FOR OLTC
\begin{tabular}{|c|c|}
\hline Assumed OLTC costs & \\
\hline $250 \mathrm{kVA}$ & $27^{\prime} 000 \mathrm{CHF}$ \\
\hline $400 \mathrm{kVA}$ & $31^{\prime} 000 \mathrm{CHF}$ \\
\hline $600 \mathrm{kVA}$ & $35^{\prime} 000 \mathrm{CHF}$ \\
\hline $800 \mathrm{kVA}$ & $37^{\prime} 000 \mathrm{CHF}$ \\
\hline $1000 \mathrm{kVA}$ & $41^{\prime} 000 \mathrm{CHF}$ \\
\hline
\end{tabular}

\section{VC with LVR}

LVR helps to improve voltage profiles locally and reduces losses on the distribution lines, while the distribution transformer with OLTC acts in a wider manner. However, the optimal location of the LVR depends on topology assumptions and the load/generation behaviour forecasts (depicted in Figure 4). For the LVR impact investigation, a voltage regulator with a standard control range of $\pm 6 \%$ or $\pm 24 \mathrm{~V}$ is used. The control range comprises 9 steps with 5 -volt deadband. This corresponds to a gradation of \pm 4 steps and is effective on the primary side of the LVR. Per stage, the secondary voltage thus changes by $\pm 1.5 \%$. The advantage of the voltage regulator is that it only changes the voltage amplitude. As a result, there is no active power limitation of the PV system and the entire produced power can be fed in. The price for an LVR is presented in Table III and it depends on the controller performance. 


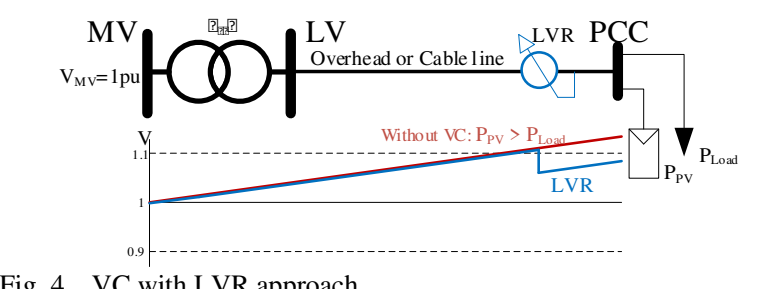

Fig. 4. VC with LVR approach

TABLE III. CAPITAL COSTS FOR LVR
\begin{tabular}{|c|c|}
\hline Assumed LVR costs & \\
\hline $20 \mathrm{kVA}$ & $11^{\prime} 000 \mathrm{CHF}$ \\
\hline $110 \mathrm{kVA}$ & $23^{\prime} 000 \mathrm{CHF}$ \\
\hline $175 \mathrm{kVA}$ & $26^{\prime} 000 \mathrm{CHF}$ \\
\hline $250 \mathrm{kVA}$ & $29^{\prime} 000 \mathrm{CHF}$ \\
\hline
\end{tabular}

\section{Voltage Dependent $P Q(V)$ Control with $P V$ Inverters}

The voltage dependent power control $(\mathrm{PQ}(\mathrm{V})$ control) using PV inverters can be implemented according to the specification of the local distribution system operator and is already possible for several products on the market VKW [19]. A possible control ramp, implementing the PQ(V) control with a mean value at $1.03 \mathrm{pu}$ is depicted in Figure 5 [20]. These characteristics were chosen according to maintain the DACHCZ-regulations. The $\mathrm{PQ}(\mathrm{V})$ control with different control methods has been implemented in the Matpower environment [11] and was applied to the different real grids. The technical feasibility was evaluated by comparing the maximum voltage at the weakest node in the LVDG with and without $\mathrm{PQ}(\mathrm{V})$ control.

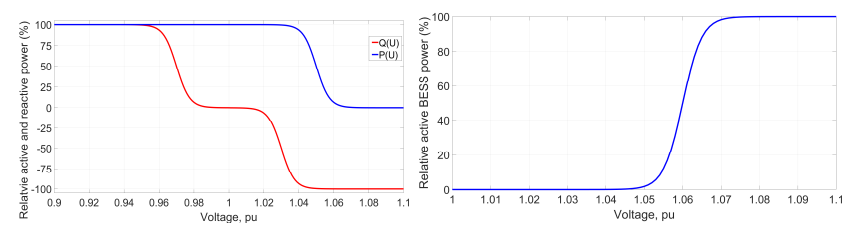

Fig. 5. $P Q(V)$ (left) and $P \_B E S S(V)$ (right) control of a inverter.

In order to deploy reactive power while simultaneously keeping the active power output at $100 \%$ the apparent power output of the PV inverter needs to be oversized. For the maximum reactive power control at $\cos \square=0.9$ the apparent power of the inverter thus has to be oversized 1.11 times. Active power curtailment over time results in a tangible yield loss of the PV plant and thus a cost share induced by the $\mathrm{PQ}(\mathrm{V})$ control. Further active power losses may be caused by the heat dissipation on the power lines due to the additional reactive power circulation in the LVDG. In the analysed grids the costs for yield losses were accounted for with $60 \mathrm{CHF} / \mathrm{MWh}$ and the costs for reactive power compensation were estimated at $41 \mathrm{CHF} / \mathrm{MVarh}$ [21],[22].

\section{E. VC with Demand Side Management}

Due to high volatility of local demand in LVDG and uncertain availability during time, using flexible loads for the local VC does not seem to be a reliable solution according to [23] and Figure 6. The measurements represent the small office active power consumption behaviour per month with pronounced consumption per working days and weekends without PV generation. The total consumption in July and August was 200kWh and $227 \mathrm{kWh}$, respectively. Extension of existing demand with thermal loads (hot water boilers, heat pumps) will allow to utilize PV produced energy and decrease voltage violations in the grid. However, such extension will not provide certain and stable solution in long-term. Based on these findings, the use of DSM for voltage control in LVDG is not considered as reliable.
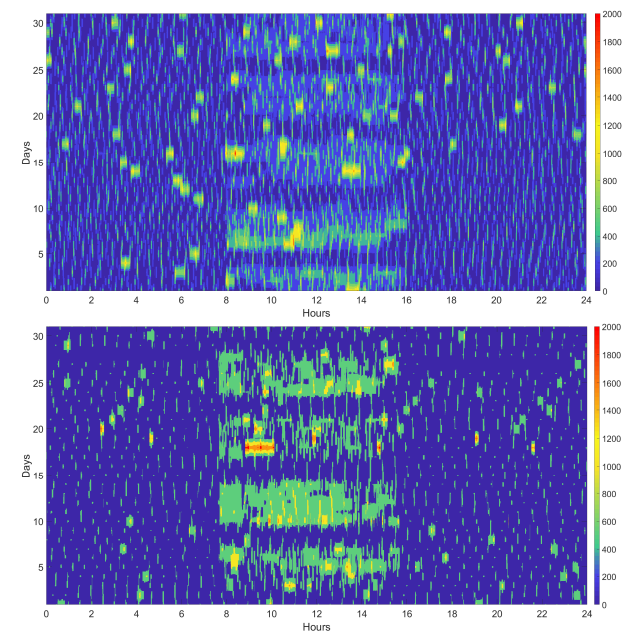

Fig. 6. Consumption distribution of office in July and August in watts with 10 second time step

\section{F. VC with Battery Energy Storage Systems}

The voltage dependent control (P_BESS(V) control) using BESS inverters can be implemented according to the specification of the local distribution system operator. A possible control ramp, implementing the P_BESS(V) control with a mean value at $1.06 \mathrm{pu}$ is depicted in Figure 5. Active power charge beyond 1.05 pu counteracts voltage rise at the node (e.g. high PV feed-in) as depicted in Figure 7. It was assumed that all BESS accumulated energy during voltage violations was used to cover consumption. Costs per usable kilowatt hour including battery inverter costs are assumed in range from $700 \div 4200 \mathrm{CHF} / \mathrm{kWh}[24]$.

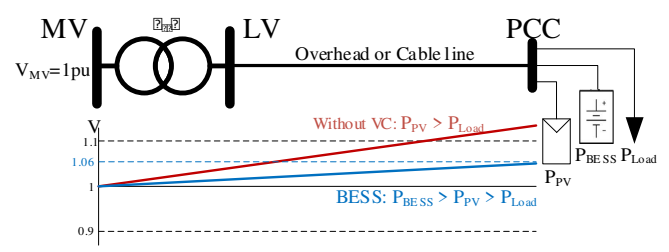

Fig. 7. VC with BESS

\section{ARTIFICIAL LVDG FOR INVESTIGATION}

For a wider spectrum of investigations, an Artificial grid (AG) (see Figure 8) was implemented for different VC solution analysis, changing grid topology, line length variation from $10 \mathrm{~m}$ till $1510 \mathrm{~m}$, installed PV from 0 till $280 \mathrm{kWp}$, and load variation from $165 \mathrm{~kW}$ till $63 \mathrm{~kW}$. The load was adjusted according to the line length and maximal allowable current value for the cable type NS-GKN $3 \times 150 / 150$ with $70 \%$ loading: longer line, smaller load.

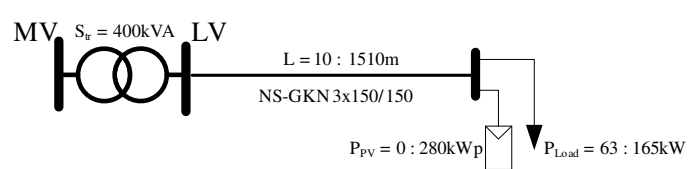

Fig. 8. Single line diagram of the Artificial LVDG

OLTC control solution is not investigated in particular case, due to small influence on the voltage at PCC. With an increase in the line length, the local control of the transformer becomes insensitive to voltage violation at the end of the line.

Figure 9 presents the investigated grid behaviour without $\mathrm{VC}$ and represents maximal voltage in PCC, active and reactive energy losses with costs for losses per Year. At shorter distances $(<460 \mathrm{~m})$, the installed PV power $(280 \mathrm{kWp})$ does not violate the voltage. At longer distances (1510m) voltage violations appear at $80 \mathrm{kWp}$ installed PV power. 

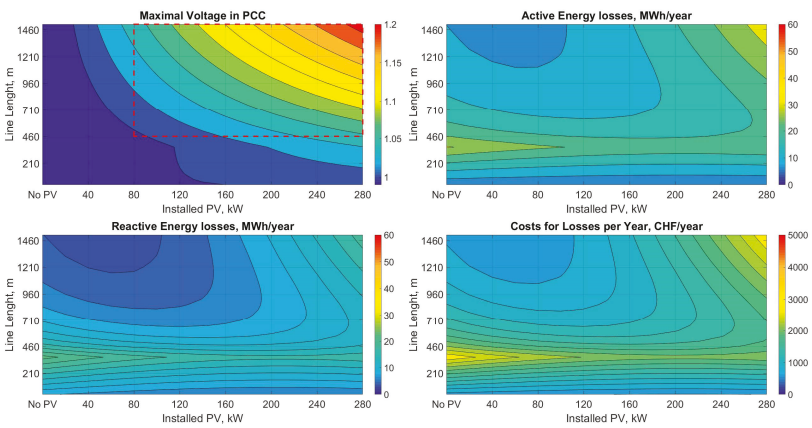

Fig. 9. AG behaviour without VC

Figure 10 presents $\mathrm{PV} \mathrm{Q}(\mathrm{V})$ control and represents the necessary investments for oversizing PV and covers additional active and reactive losses. Investment costs for oversizing of $\mathrm{PV}$ are assumed $250 \mathrm{CHF} / \mathrm{kW}$. A higher reactive power flow on the circuits will lead to higher losses on the lines as well as an increased load on transformers and lines.

Figure 11 presents $\mathrm{PV} P Q(\mathrm{~V})$ control and represents necessary investments for oversizing PV and covers additional active and reactive losses with reimbursement of active power curtailment. The reimbursements of active power curtailment were accounted for with $50 \mathrm{CHF} / \mathrm{MWh}$. The investments to accommodate high share of PV increases significantly because of the arising amount of active power curtailment. A study of the ZHAW [25] compares the total loss of energy production in a year according to different levels of power limitation on the inverter: $80 \%$ results in $1.0 \%$, $70 \%$ in $4.4 \%, 60 \%$ in $10.4 \%$ loss of annual production.

Figure 12 presents LVR control and represents necessary investments for device installation and covers additional active and reactive losses. Investment costs of LVR are assumed according to Table III with additional costs from Table I. This solution and costs are suitable for cases with concentrated generation. In the case of highly distributed generation, the necessary investment will increase depending on number of installed LVRs across the network.
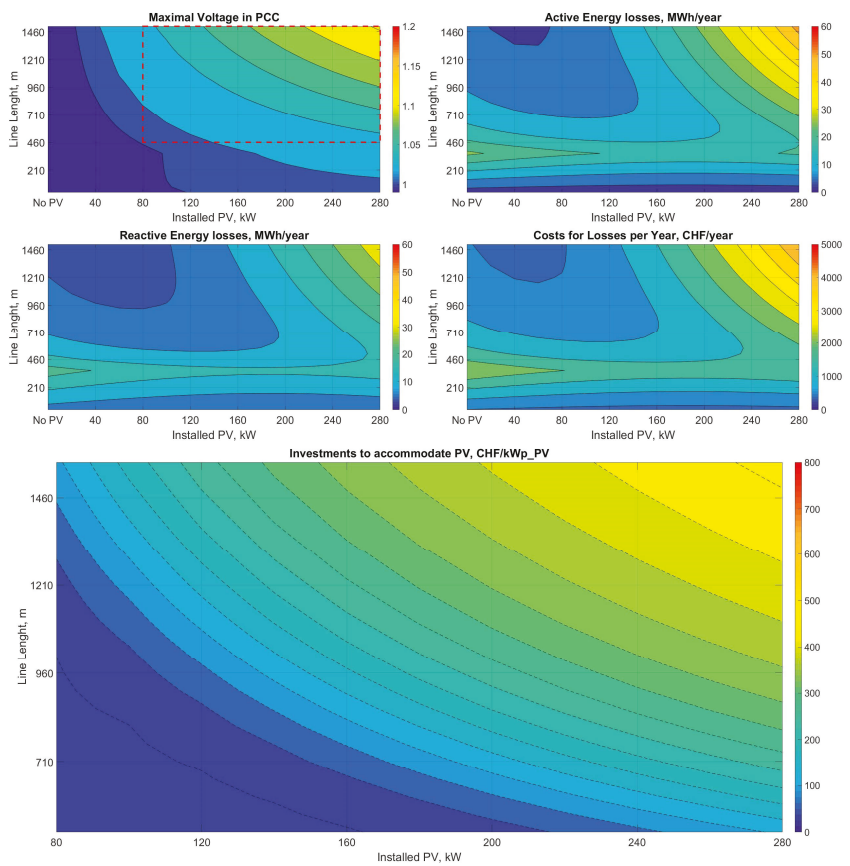

Fig. 10. AG behaviour with PV Q(V) control
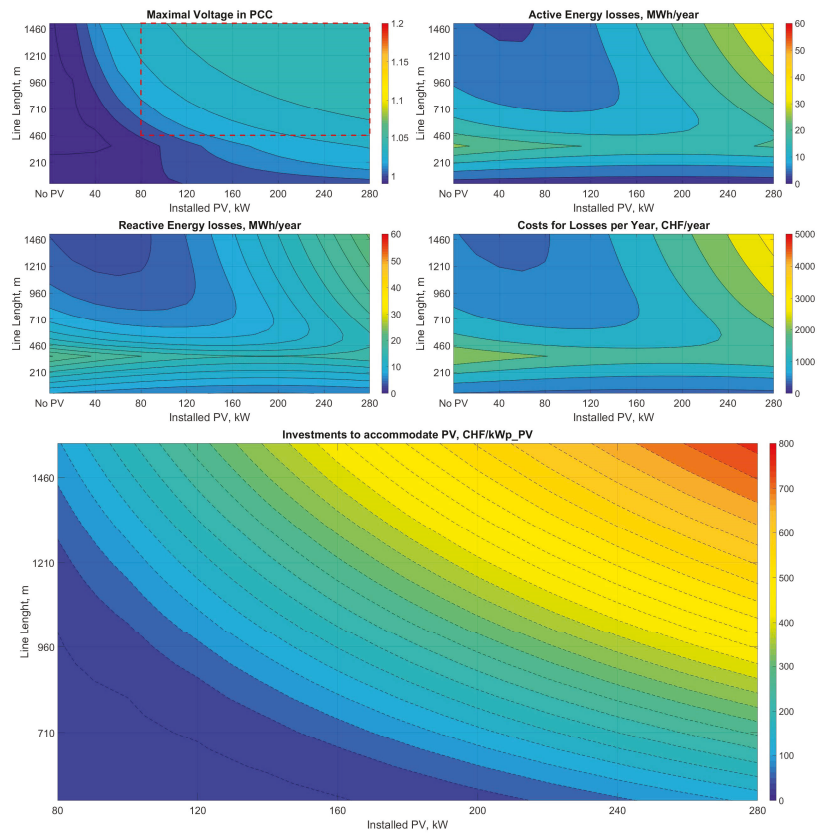

Fig. 11. AG behaviour with PV PQ(V) control
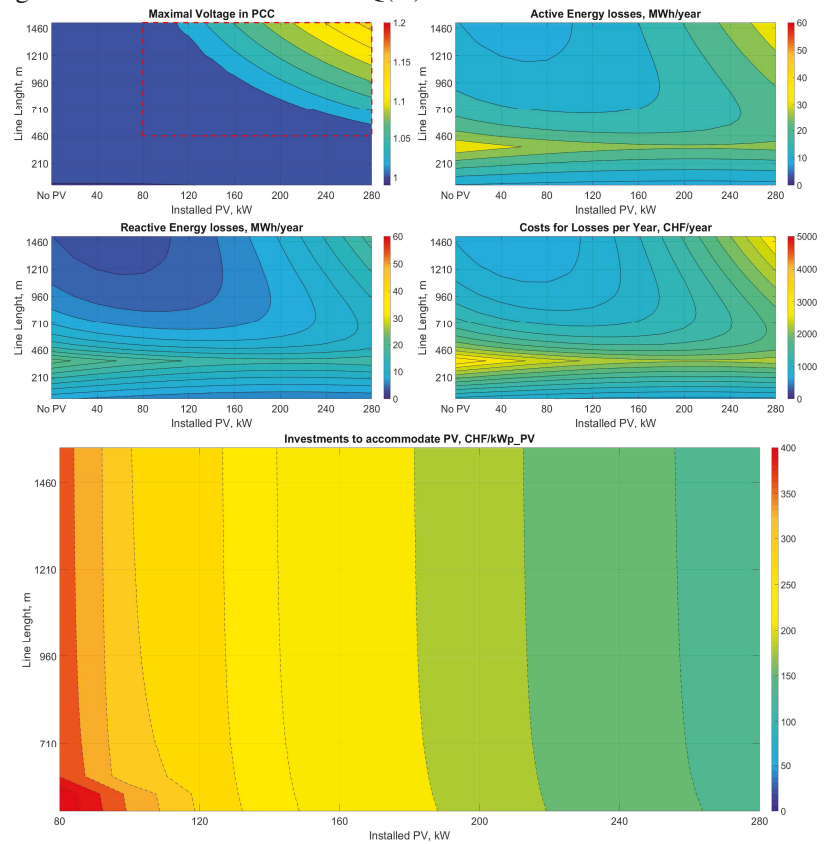

Fig. 12. AG behaviour with LVR - Mintap=0.94 Maxtap=1.06

Figure 13 presents grid reinforcement and represents necessary investments for reconstruction and covers additional active and reactive losses (losses reduction). Reconstruction of NS-GKN 3x150/150 cable with NS-GKN $3 \times 240 / 240$ cable $\mathrm{R} 0=0.0754 \cdot / \mathrm{km} \mathrm{X0}=0.072 \cdot / \mathrm{km}$ and the costs are assumed $150 \mathrm{CHF} / \mathrm{m}$.

Figure 14 presents extended grid reinforcement. Reconstruction of NS-GKN $3 \times 150 / 150$ cable with two parallel NS-GKN $3 \times 240 / 240$ cables. Costs for particular reinforcement are assumed $30 \%$ higher than previous reinforcement. Extended grid reinforcement solves voltage violations, increasing grid hosting capacity and allowing increase distance from $460 \mathrm{~m}$ till $1510 \mathrm{~m}$.

Figure 15 presents BESS control and represent necessary investments in storage and covers additional active and reactive losses. BESS is investigated only for VC purpose and investment costs for installation are assumed $700 \mathrm{CHF} / \mathrm{kWh}$ to prevent voltage violations. 

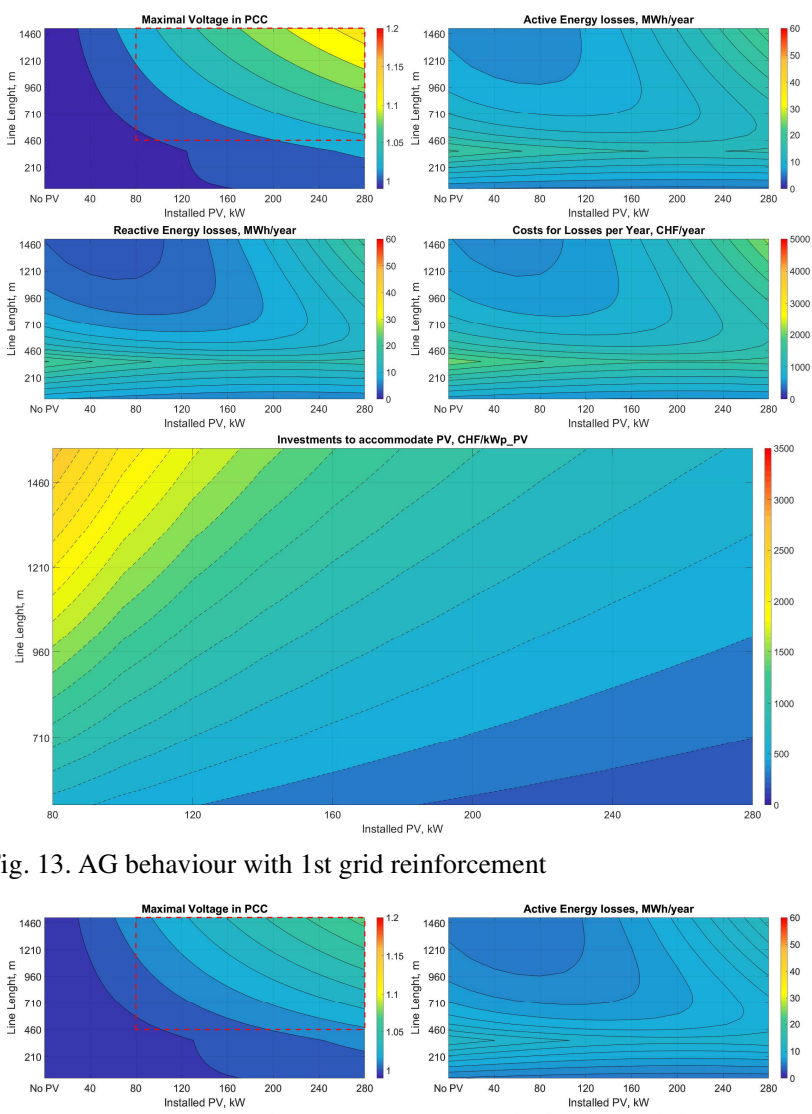

rid reinforcement
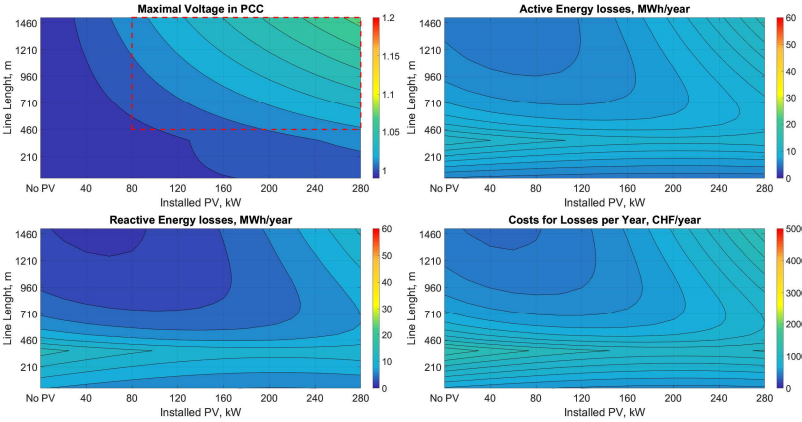

Costs for Lossses per Year, CHF
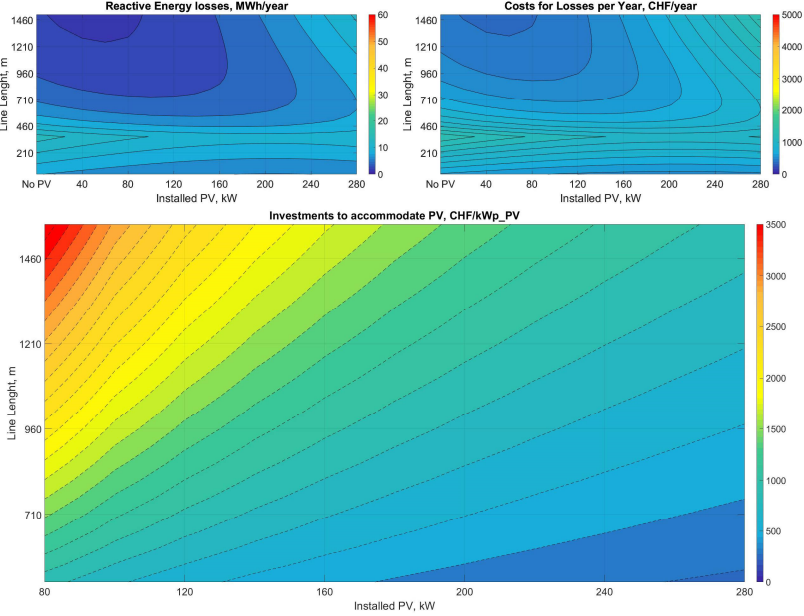

Fig. 14. AG behaviour with 2nd grid reinforcement

Investigated $\mathrm{AG}$ provides a clear comparative analysis for different local VC solutions in the middle and long-term horizon. There is not one major VC solution for every LVDG topology but rather there are different solutions for the different topologies. Q(V), PQ(V) and LVR solutions can be identified as more appropriate and promising from the investment and functionality point of view, in comparison with grid reinforcements.
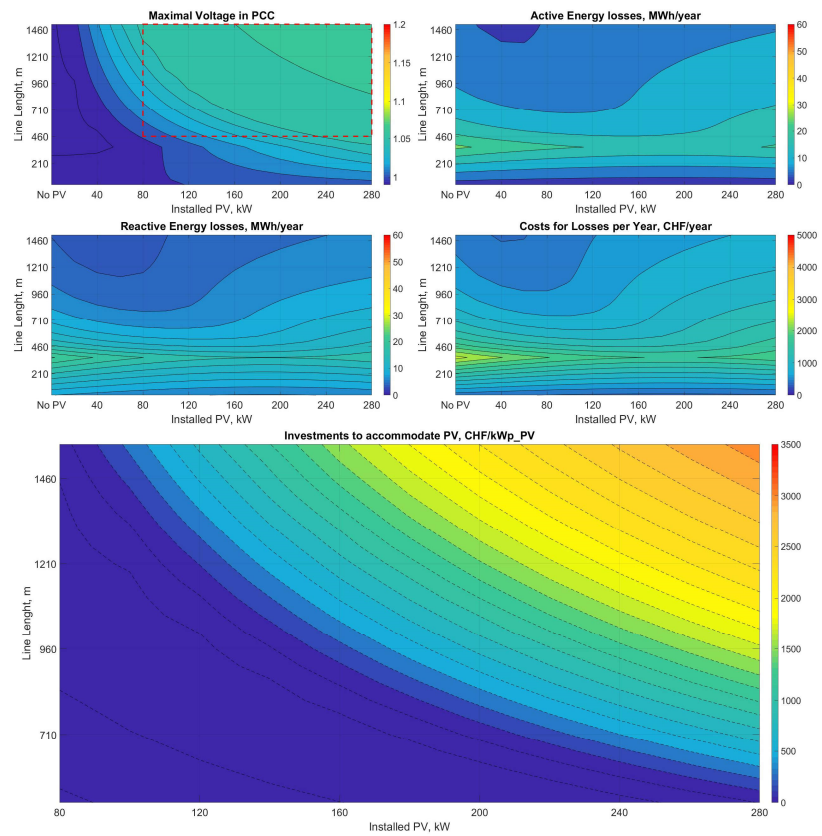

Fig. 15. AG behaviour with BESS

\section{ECONOMIC EVALUATION OF LOCAL VC SOLUTIONS}

The technical and economic analysis was carried out between different solutions and was applied to five different real grids in Switzerland and one from Southern Germany. The allocation of PV plants was considered according to the local DSOs estimations. These results were used to classify the methods for various LVDG categories and to generate the ranking matrix presented in Table IV. In the matrix elements, the typical characteristics are mentioned, e.g. investments, which are required to accommodate a given percentage of PV power generation relative to local consumption in the distribution network. The definition of grid classes is given by the aggregation of several sectors of the distribution grid that provide similar services. Each class consists of the grid itself and the types of consumers and distributed producers. The presented results are based on real investigated grids and achieved technical solutions for 25-year estimation period, $\mathrm{CHF} / \mathrm{kWp}$ _PV. Small and medium industrial grids were neglected in investigation due to short lines and powerful connections. Voltage violation in current grids is not expected with high share of PV. Urban areas were with strong grids, and voltage violations with considered PVs not appear, however PQ(V), Q(V), LVR and OLTC solutions was applied to mitigate voltage. Hamlets grid was with highest voltage violation and maximum voltage at the weakest node was $21.7 \%$ over the nominal voltage. The best performance showed the $\mathrm{PQ}(\mathrm{V})$ control strategy with a mean value of $1.02 \mathrm{pu}$, where the voltage could be reduced by $16.4 \%$ and grid reinforcement where the voltage could be reduced by $14.7 \%$.

TABLE IV. ECONOMIC EVALUATION OF DIFFERENT SMART GRID TECHNOLOGIES FOR TYPICAL NETWORK CLASSES, CHF/KWP_PV

\begin{tabular}{|c|c|c|c|c|c|c|c|}
\hline \multirow[b]{2}{*}{ Grid type } & \multicolumn{7}{|c|}{ Alternative Solutions } \\
\hline & Grid Reinforcement & PQ(V) ctrl & $Q(V)$ ctrl & LVR & OLTC & BESS & DSM \\
\hline 1: Industry & N/A & N/A & N/A & N/A & N/A & N/A & N/A \\
\hline 2: Small industry: & N/A & N/A & N/A & N/A & N/A & N/A & N/A \\
\hline 4: Urban area with multi-family houses & Strong grid & $50 \div 70$ & $50 \div 70$ & $40 \div 50$ & $50 \div 60$ & Strong grid & N/A \\
\hline 5: Urban areas with business centres or schools & Strong grid & $40 \div 60$ & $40 \div 60$ & $75 \div 85$ & $55 \div 65$ & Strong grid & N/A \\
\hline 6: Village Centres & Strong grid & $30 \div 35$ & $30 \div 35$ & $70 \div 80$ & $90 \div 100$ & Strong grid & N/A \\
\hline 7: Village peripheries & $160 \div 450$ & $90 \div 130$ & $90 \div 125$ & $50 \div 60$ & $70 \div 80$ & $>350$ & N/A \\
\hline 8: Hamlets & $490 \div 1700$ & $390 \div 430$ & Inf.sol & Inf.sol & Inf.sol & $>2 ’ 200$ & N/A \\
\hline
\end{tabular}




\section{RESULTS AND DISCUSSIONS}

- The topology of the system influences the voltage profile on LV grids. Nowadays, it is no longer possible to assume unidirectional energy fluxes directed from the MV grid to the loads and decreasing voltages along the strings. The integration of PV DG with a high integration level changes the topology of the grids, causing voltage profiles to decrease or increase depending on the quantity of active power injection into the string.

- The proportional relationship between the active power infeed and the likelihood of over-voltages to appear on the grid is directly related to the active power density installed in a region. An urban area is characterized for small line distances, high population density and high concentration of DG. A rural area is characterized for long line distances, a low population density and therefore low concentration of DG. The behaviour of the voltage violations on the types of distribution grids is totally different. It is inferred that overvoltage violations are more likely to appear in rural areas than in urban areas, due to the ratio between low consumption and high generation.

- Due to the low ratio $\mathrm{X} / \mathrm{R}$ of $\mathrm{LV}$ grids, reactive power regulation as VC is less effective in LV as in HV grids. This indicates a more moderate effect on the distribution grid with solutions based on reactive power regulation. On the other hand, this ratio is the reason why technologies based on active power regulation are more suitable to provide solutions to the LV grid problematic.

- The concept of selectivity can be applied to the VC context as the capacity of a device to improve the voltage profile locally with minimal influence on other strings of the distribution grid. e.g. an OLTC located at the MV/LV transformer affects the voltage profile of all the strings attached to it. Meanwhile, an LVR can act locally at specific nodes that exhibit voltage violations with less influence over other strings.

- Because of its simple topology, voltage control in rural distribution grids is easier to implement. This kind of grids are more likely to exhibit overvoltage boundary violations in any case where they were implemented through cables. On the contrary, voltage control in urban distribution grids tends to be more complicated, since a mixture of overvoltages and undervoltages characterizes these grids at the same time. For this type of grids, a combination of voltage control technologies acting over a big area of the grid and selectively over dedicated nodes are suggested.

- Modern inverters can control the active and reactive power with respect to the actual grid voltage. This fact introduces new opportunities not only for the DSO, but also for the regulatory authority. The DSO should have the possibility to operate the grid in a wider voltage range up to the $1.1 \mathrm{pu}$. Therefore, if the voltage reaches $1.1 \mathrm{pu}$, the feed-in power of the inverter has to be decreased linearly to zero as it is already implemented by the Austrian authority in TOR D4 [26].

- All the solutions summarized in this paper have the capability of mitigating voltage violations in order to avoid the grid reinforcement as an objective, there are still cases where it is inevitable.

\section{CONCLUSIONS}

This work presents a palette of possible solutions to voltage boundary violation problems, although, none of these solutions can be identified suitable to every possible topology of the distribution grid. The optimal solution regarding $\mathrm{VC}$ in LVDG shall be a combination of technologies that allows different grades of selectivity and that is capable to adapt to the topology necessities of the grid. Q(V), PQ(V) and LVR solutions can be identified as more appropriate and promising from the investment and functionality point of view, in comparison with grid reinforcements.

\section{ACKNOWLEDGMENT}

This research is funded by the Swiss Federal Office of Energy (SFOE) under the contract number SI/501370-01 and is also part of the activities of SCCER FURIES, which is financially supported by the Swiss Innovation Agency (Innosuisse SCCER program).

\section{REFERENCES}

[1] Prognos, "Die Energieperspektiven für die Schweiz bis 2050. Energienachgefrage und Elektrizitätsangebot in der Schweiz 2000-2050" Technical Report; Prognos AG: Basel, Switzerland, 2012.

[2] R. Rechsteiner, "Energiestrategie 2050: Zwischenbilanz beim Ausbau neuer erneuerbarer Energien - Analyse und Ausblick zur Mittelverwendung aus dem Netzzuschlag" Basel, November 2019

[3] BFE-Studie: "Schweizer Solarpotenzial grösser als benötigt", 15. April 2019 www.swissolar.ch

[4] VSE, DACHCZ - "Technische Regeln zur Beurteilung von Netzrückwirkungen", 2007

[5] EN 50160, "Voltage Characteristics of electricity supplied by public distribution networks", 2011

[6] Z. Krishans, A. Mutule, Y. Merkuryev, I. Oleinikova, "Dynamic management of Sustainable Development: Methods for Large Technical Systems", in Hardcover, 1st ed., London, Springer, 2010.

[7] T. Stetz, K. Diwold, M. Kraiczy, D. Geibel, S. Schmidt, and M. Braun, "Technoeconomic assessment of voltage control strategies in low voltage grids," IEEE Trans. Smart Grid, vol. 5, no. 4, pp. 2125-2132, Jul. 2014.

[8] IEA-PVPS, "Do It Locally: Local Voltage Support by Distributed Generation A Management Summary", 2017

9] S. Hashemi, J. Østergaard, "Methods and strategies for overvoltage prevention in low voltage distribution systems with PV". IET Renew.Power Gener., vol. 11, no. 2, pp. 205-214, 2017.

[10] B. Bayer, P. Matschoss, H. Thomas, A. Marian, "German experience with integrating PV systems into the low-voltage grids". Renew. Energy 2018, 119,.

[11] F. Carigiet, F.P. Baumgartner, P. Korba, R. Knecht, M. Koller, M. Niedrist, "Optimisation of the Load Flow Calculation Method in Order to Perform TechnoEconomic Assessments of Low-Voltage Distribution Grids". 33rd EUPVSEC, Amsterdam, 2017

[12] EPRI, "The Open Distribution System Simulator OpenDSS®", 2016

[13] UVEK legt Kapitalkostensatz für Stromnetze für das Tarifjahr 2020 fest, available: https://www.admin.ch/

[14] Zielnetzplanung CH light, "Methodik zur langfristigen Optimierung für kleine und mittlere Verteilnetze". BFE, 2017

[15] VSE, Branchenempfehlung Strommarkt Schweiz Einheitskosten, 2017

[16] VSE, Kostenrechnungsschema für Verteilnetzbetreiber der Schweiz, 2018.

[17] H. Reist "Spannungsqualität und -regelung im Niederspannungsnetz," Bachelor Thesis, ZHAW, 2016

[18] L.Baumgartner, "Economic voltage regulation in electrical distribution grids," Master Thesis, ZHAW, 2015

[19] VKW, Liste untersuchte Wechselrichter Vorarlberg Netz., 2018

[20] R. Knecht, F. Carigiet, A. Schwab, P. Korba, F.P. Baumgartner, "TechnoEconomic Evaluation of Voltage Dependant Active and Reactive Power Control to Reduce Voltage Violations in Distribution Grids". 34rd EUPVSEC, 2018

[21] Internal information from the the electric utility EKZ, Dietikon, Switzerland

[22] A. Schwab "Analyse der Spannungshaltung in Niederspannungsnetzen bei hohem Solarstromanteil für die Elektromobilität," Bachelor Thesis, ZHAW, 2018

[23] A. Obushevs, I. Oleinikova, A. Mutule, "Demand side management platform for HAN flexibility estimation with agent control". EEM16, Porto. 2016

[24] T. Baumann, F.P. Baumgartner, "Home Batteriespeicher, Studie für solarspar". ZHAW, 2017

[25] F. Carigiet, F.P. Baumgartner, Verification of Measured PV Energy Yield Versus Forecast and Loss Analysis. 28th EUPVSEC, Paris, 2013

[26] TOR D4. Technische und organisatorische Regeln für Betreiber und Benutzer von Netzen Teil D: Besondere technische Regeln Hauptabschnitt D4: Parallelbetrieb von Erzeugungsanlagen mit Verteilernetzen. E-Control, 2016. 